\title{
PROLIFERATION OF THE SUPERFICIAL EPITHELIUM OF OVARIES IN SENILE FEMALE RATS FOLLOWING ORAL ADMINISTRATION OF CONJUGATED EQUINE ESTROGENS
}

\author{
Sergio Eduardo Perniconi, ${ }^{\mathrm{I}}$ Manuel de Jesus Simões, ${ }^{\mathrm{I}}$ Ricardo dos Santos

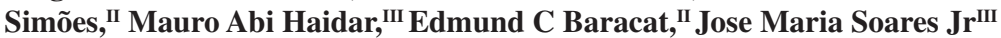

doi: $10.1590 / \mathbf{S 1 8 0 7 - 5 9 3 2 2 0 0 8 0 0 0 3 0 0 0 1 6}$

\begin{abstract}
Perniconi SE, Simões MJ, Simões RS, Haidar MA, Baracat EC, Soares Junior JM. Proliferation of the superficial epithelium of ovaries in senile female rats following oral administration of conjugated equine estrogens. Clinics. 2008;63:381-8.
\end{abstract}

OBJECTIVE: To evaluate the effect of different concentrations of estrogen on the ovarian superficial epithelium in senile female rats. Design: Fifty female rats at 15 months of age and with irregular estrous cycles were selected and randomly divided into five experimental groups containing equal numbers of animals in each: GPROP, control group receiving vehicle only; GE0.05mg, group receiving conjugated equine estrogens (CEE) at a dose of $50 \mu \mathrm{g} / \mathrm{kg}$; GE0.5mg, group receiving CEE at $500 \mu \mathrm{g} / \mathrm{kg}$; GE1mg, group receiving CEE at $1 \mathrm{mg} / \mathrm{kg}$; and GE2 $\mathrm{mg}$, receiving CEE at $2 \mathrm{mg} / \mathrm{kg}$. The length of treatment was 21 days. After this period, the animals were anesthetized and the ovaries were fixed in 10\% formaldehyde and processed for routine histology. Histomorphology was analyzed by light microscopy, and histomorphometrics were evaluated using the Imagelab program.

RESULTS: In the GPROP and GE0.05mg groups, the superficial epithelium of the ovary had a simple cuboidal shape, and as the estrogen dose increased, the epithelium thickened, with pseudo-stratified or stratified epithelium appearing in the GE2mg group. The animals in the group given the highest estrogen dose (GE2mg) showed the thickest ovarian epithelium and the largest perimeter and surface area of the surface ovarian epithelium $(P<0.01)$. However, the difference in epithelium thickness between the GE0.5mg and GE1mg groups was only slight.

CONCLUSION: Our data suggest that CEE at a dose of $2 \mathrm{mg} / \mathrm{kg}$ may induce marked proliferation of rat ovarian epithelium.

KEYWORDS: Estrogens. Superficial epithelium. Ovary. Animal Model.

\section{INTRODUCTION}

Ovarian carcinoma has an extremely poor prognosis and is one of the leading causes of morbidity and mortality in women with cancer. In general, the diagnosis of ovarian cancer occurs when the clinico-surgical stage is already quite advanced; in fact, $70 \%$ of women diagnosed with this condition are in stage III or IV. ${ }^{1}$ Cancer recurs in about $75 \%$

\footnotetext{
${ }^{\mathrm{I}}$ Histology and Cellular Biology Division, Morphology Department of UNIFESP - São Paulo/SP, Brazil.

II LIM-58, Faculdade de Medicina da Universidade de São Paulo - São Paulo/SP, Brazil.

III Gynecology Department, Faculdade de Medicina da Universidade Federal de São Paulo - São Paulo/SP, Brazil.

jsoares415@hotmail.com

Received for publication on December 27, 2007

Accepted for publication on March 10, 2008
}

of patients with advanced primary tumors, even after initial therapy. ${ }^{2}$ The prognosis for patients with recurring disease remains poor, with a $23 \%$ five-year survival rate overall and a $14 \%$ survival rate for stages III and IV. ${ }^{3}$ For these reasons, the molecular pathways involved in the progression of ovarian cancer are excellent candidates as targets for treating and even preventing the disease.

The gonadotropic theory of ovarian cancer postulates that it develops when the hypophysial gonadotropins (luteinizing hormone $[\mathrm{LH}]$ and follicle-stimulating hormone $[\mathrm{FSH}]$ ) stimulate excessive growth of ovarian tissue. ${ }^{4}$ Pregnancy and the use of oral contraceptives containing progestagens suppress the release of gonadotropins, and may protect against development of ovarian cancer, particularly cancer of the ovarian superficial epithelium. ${ }^{5}$ Thus, it is possible that when ovarian cancer arises due to the superficial 
epithelium of the ovary, it may be the result of excessive hormonal stimulation of the epithelial cells either on the surface of the ovary or within inclusion cysts. In addition, it is possible that excessive gonadotropin secretion mediates the growth stimulation. Post-menopausal women and women in menopausal transition have high levels of circulating gonadotropins, and patients with polycystic ovary syndrome have persistently elevated levels of luteinizing hormone. These two situations of increased gonadotropins may be risk factors for the development of ovarian cancer. ${ }^{6,7}$ Another hypothesis regarding ovarian cancer development is that increased risk may be associated with incessant ovulation, which involves chronic formation of stromal epithelial clefs and inclusion cysts following ovulation. ${ }^{5}$ In fact, repetitive cycles of epithelial insult and repair during ovulation promote genomic instability, which renders the superficial epithelial layer vulnerable to carcinogenesis. ${ }^{8}$

Estrogen is a trophic hormone with anabolic properties, and it performs several functions in female biology. ${ }^{9} \mathrm{~A}$ significant reduction in estrogen levels in a woman may produce harmful effects such as an increased risk of osteoporosis and atrophy of the genital organs. Although hormone replacement therapy with exogenous estrogen may mitigate these changes, some women are susceptible to hormone-dependent neoplasias such as breast and uterine cancers. ${ }^{10-12}$ Some researchers believe that estrogen alone may play a role in the development of ovarian cancer, especially in malignancies related to the ovarian superficial epithelium. ${ }^{13}$ Epidemiological studies suggest that administration of estrogen to postmenopausal women may increase their risk of developing ovarian cancer. ${ }^{14}$ Furthermore, estrogen levels in ovarian tissue are at least 100 times higher than circulating estrogen levels and are even higher than those in ovarian follicular fluids.

Elevated estrogen levels stimulate proliferation of ovarian superficial epithelial cells by activating cellular estrogen receptors. This promotes genetic instability because of the frequent rounds of DNA replication and recombination. ${ }^{15}$ The mitogenic effects of estrogen on ovarian cancer cells are a result of several signaling pathways, including regulation by growth factors and cytosines, ${ }^{16} \mathrm{Bcl}-2,{ }^{17}$ activation of the c-myc protooncogene ${ }^{18}$ and TGF-.${ }^{19}$ Estrogen signaling activates interleukin- $6^{20}$ induces a rise in the circulating levels of growth factor. In a recent study using complementary DNA, several cancer-related genes regulated by estradiol were identified, including genes involved in cell cycle regulation (CCNB1), apoptosis (TRAP1), transcription (TFAP4), and cellular signaling (LCN2). ${ }^{21}$ Additionally, the estradiol metabolite 4-hydroxy estradiol enhances the expression of both inducible factor hypoxia- $1 \alpha$ (HIF-
$1 \alpha)$ and vascular endothelial growth factor (VEGF) in cancerous ovarian cells. This enhancement may play an important role in the progression and neoangiogenesis in tumors via phosphatidylinositol 3-kinase/Akt/FRAP signaling. ${ }^{22}$ Moreover, estrogen signaling may decrease GnRH and GnRHR expression, thus significantly reducing the ability of GnRH to inhibit the proliferation of ovarian cancer cells. ${ }^{23}$ Estrogens also affect tumor progression by promoting invasion and metastasis through up-regulation of some genes involved in remodeling the cytoskeleton or extracellular matrix, such as fibulin- $1 \mathrm{C}^{24}$ and fibernectin. ${ }^{21}$

In animals, continuous administration of estradiol (17beta-estradiol) leads to decreased ovulation and promotes proliferation of the ovarian superficial epithelium ${ }^{25}$ as well as the emergence of ovarian cysts. In rabbits, administration of 17beta-estradiol estrogen induces the formation of papilae on the ovarian superficial epithelium (OSE), which is histologically similar to the lesions found in low-malignancy serous neoplasia in human ovaries. ${ }^{26,27}$ The senile female rat does not undergo the hypoestrogenism secondary to ovarian failure that occurs in postmenopausal women, but when the rat is acyclic it maintains high levels of gonadotropins. ${ }^{28}$ High levels of circulating gonadotropins in acyclic rats is a good model system for studying the effects of unopposed estrogens on the OSE.

Conjugated equine estrogens (CEE) are commonly used in postmenopausal hormone replacement therapy (HRT). These hormones are a combination of soluble estrogens from the urine of pregnant mares, and they include several biologically active components such as estrone, estradiol, and its respective sulphates, and sulphates of equine estrogens (equilin and equilenin). It should be pointed out that after absorption into the bloodstream, equilin and equilenin are converted into 17beta-dihydroequilin and 17beta-dihydroequilenin, respectively. When conjugated estrogens are orally administered, part of the combination is absorbed as sulphate and the rest is hydrolyzed in the digestive tract and sulphated again after absorption. Nonconjugated estrogens may be interconverted in the liver and target tissues. These nonconjugated estrogens circulate bound to a globulin that transports sex hormones, whereas sulphated forms bind with high affinity to albumin. The pharmacokinetic parameters of conjugated equine estrogens are complex. When bound to albumin, the sulphated forms of estrone, equilin, equilenin, and their 17-dihydro metabolites are known to circulate at higher concentrations than nonconjugated estrogens.

However, the effects of these hormones on the OSE have not been clarified. Results from epidemiological studies investigating the effects of HRT on carcinogenesis are contradictory. Several studies have been undertaken, 
with some showing a significant increase in cancer risk, ${ }^{13,29}$ and others reporting no significant positive associations. ${ }^{30,31}$ The inconsistencies among these studies may be due to differences in methodology or lack of control lack of control over conflicting factors. ${ }^{30,}{ }^{32-35}$ For this reason, we decided to evaluate the carcinogenic effects of different doses of conjugated equine estrogens in senile female rats.

\section{MATERIALS AND METHODS}

Fifty rats (Rattus norvegicus albinus) of the EPM-1 Wistar strain at 15 months of age were used. Average weight was 300 grams. The animals were supplied by the Center for the Development of Experimental Models in Medicine and Biology (CEDEME) of the Escola Paulista de Medicina at the Federal University of São Paulo (UNIFESP-EPM). The project design was approved by the ethics and research committee of the Federal University of São Paulo (protocol 0944/03).

The animals were transported to the Histology and Structural Biology Biotery of the Morphology Department of UNIFESP-EPM, where they were confined to plastic cages $45 \times 30 \times 15 \mathrm{~cm}$ in length, width, and height, respectively. The cages were lidded with metal grids. The rats were fed ad libitum, room temperature was maintained at $22^{\circ} \mathrm{C}$ and artificial lighting was maintained with fluorescent lamps (40 W, daylight, Phillips).

After adaption for new cages for one week, the rats were randomly divided into five study groups as follows: GPROP, which received $0.5 \mathrm{ml}$ of propylene glycol (vehicle); GE50 $\mu \mathrm{g}$, which received a daily dose of CEE of $50 \mu \mathrm{g} / \mathrm{kg}$; GE0.5mg, which received a daily CEE dose of $500 \mu \mathrm{g} / \mathrm{kg}$; GE1mg, which received a daily CEE dose of $1 \mathrm{mg} / \mathrm{kg}$; and GE2mg, which received a daily CEE dose of $2 \mathrm{mg} / \mathrm{kg}$.

The conjugated equine estrogens were diluted in $0.5 \mathrm{ml}$ of propylene glycol and administered daily in the morning by gavage for 21 consecutive days. Gavage was performed with a standard metal tube supplied by the UNIFESP-EPM Pharmacology Department.

Twenty-four hours after ingesting the final dose of CEE, the animals were anesthetized with xilazine $(20 \mathrm{mg} / \mathrm{kg})$ and ketamine $(100 \mathrm{mg} / \mathrm{kg})$ intraperitoneally. Upon laparotomy, the ovaries were removed and immediately immersed in a $10 \%$ buffered formaldehyde solution for eight hours, sliced, and the pieces were dehydrated in increasing concentrations of ethyl alcohol, diaphanized in xylol, and impregnated with and embedded in paraffin. The histological cuts $(4 \mu \mathrm{m})$ were stained with hematoxylin and eosine (HE). For morphological analysis, the cuts were observed with a light microscope under magnifications ranging from $100 \mathrm{X}$ to $400 \mathrm{X}$.

Morphometric studies were performed using a light microscope (Axiolab, Carl Zeiss) attached to an image capture system (AxionLab, Carl Zeiss). OSE measurements were made at four clock positions (12, 3, 6, and 9 o'clock) on serial sections using the AxionVision Morphometric Program (Carl Zeiss). A total of 40 consecutive observations were recorded for each animal (10 histological sections per rat). Also, the total evaluated width of the epithelium was approximately $5 \mathrm{~mm}$ per ovary (sums of all clock positions). The ovarian surface epithelial thickness, area, and perimeter were measured on profiles showing the whole epithelium from basement membrane to surface. The thickness was calculated from the average distances between the epithelium-stroma interface and the cell surface. The perimeter and area were measured by tracing the epitheliumstroma interface (Fig. 1). The area (A) and perimeter (P) formulas are as follows: $\mathrm{A}=$ length $\mathrm{x}$ width, and $\mathrm{P}=(2 \mathrm{x}$ length $)+(2 \mathrm{x}$ width $)$.

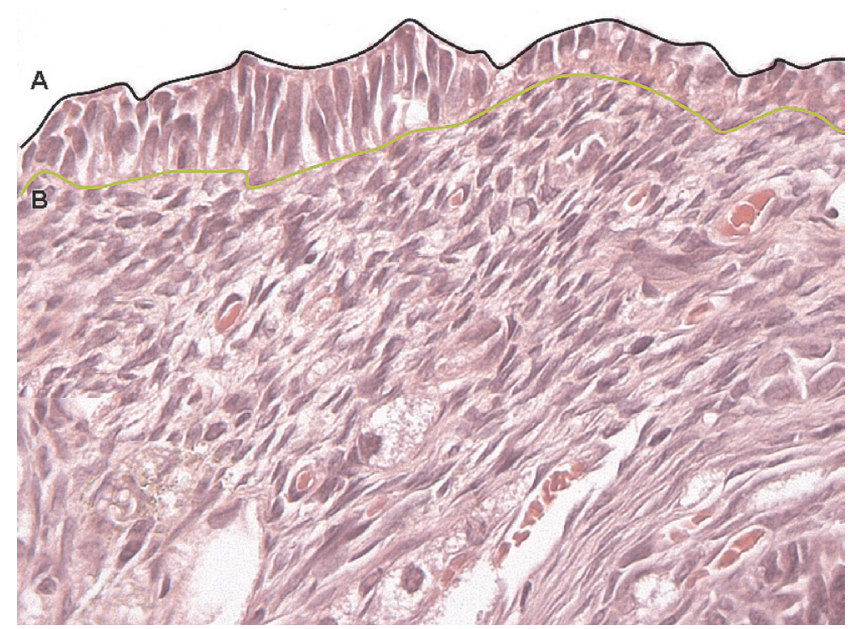

Figure 1 - Photomicrography showing the cortical region of an ovary in 1.25 $\mathrm{mm}$ extension. Letters indicate the delimitation applied to histomorphometric parameters. A) tracing along the superficial epithelial cells. B) tracing along the epithelium-stroma interface. Staining: H\&E. Magnification: 400X

The sample size was calculated based on the central limit theorem. The minimum number of animals necessary was calculated to be eight per group. To evaluate possible differences in histomorphometric parameters (perimeter, area, and thickness) among the experimental groups, the Bartlett test for assessing data homogeneity was used first, followed by the ANOVA test, and then finally by Bonferroni's post-hoc. The significance level for the rejection of the null hypothesis was fixed at 0.05 or $5 \%(\alpha<0.05)$.

\section{RESULTS}

\section{Histological Analysis}

No rats died during the experiment. The OSE was of 
simple cuboidal shape in all animals in the GPROP and GE0.05mg groups. However, as the estrogen dose increased, the lining of the epithelium thickened. This thickening was most obvious in the GE2mg group, where the epithelium was observed to be pseudo-stratified or stratified (Fig. 2). The percentage of rats with thickened ovarian superficial epithelium was $10 \%, 40 \%$, and $90 \%$, in the GE0.5mg, GE1mg, and GE2mg groups, respectively. The ovarian stroma contained a large number of interstitial cells in all groups receiving CEE. These cells were most numerous in the GE1mg and GE2mg groups (Fig. 2). The percentage of rats with increased interstitial cells was $70 \%$ and $100 \%$ in GE1mg and GE2mg, respectively. In these two groups, we also noticed leukocyte infiltration in several ovarian follicles, suggesting follicular degeneration. This phenomenon in G2mg (80\% of the rats) was more pronounced than other groups. We did not observe significant differences in the number of ovarian follicles or in the number of corpora lutea among the groups under investigation.

\section{Histomorphometric Analysis}

The animals in the GE2mg group, which received the largest dose of CEE $(2 \mathrm{mg} / \mathrm{kg})$, showed the largest area $\left(56.63 \pm 1.91 \mu^{2} \times 10^{-3}\right)$, perimeter $(23.74 \pm 6.81 \mathrm{~mm})$ and thickness $(10.41 \pm 0.18 \mu \mathrm{m})$ of OSE when compared

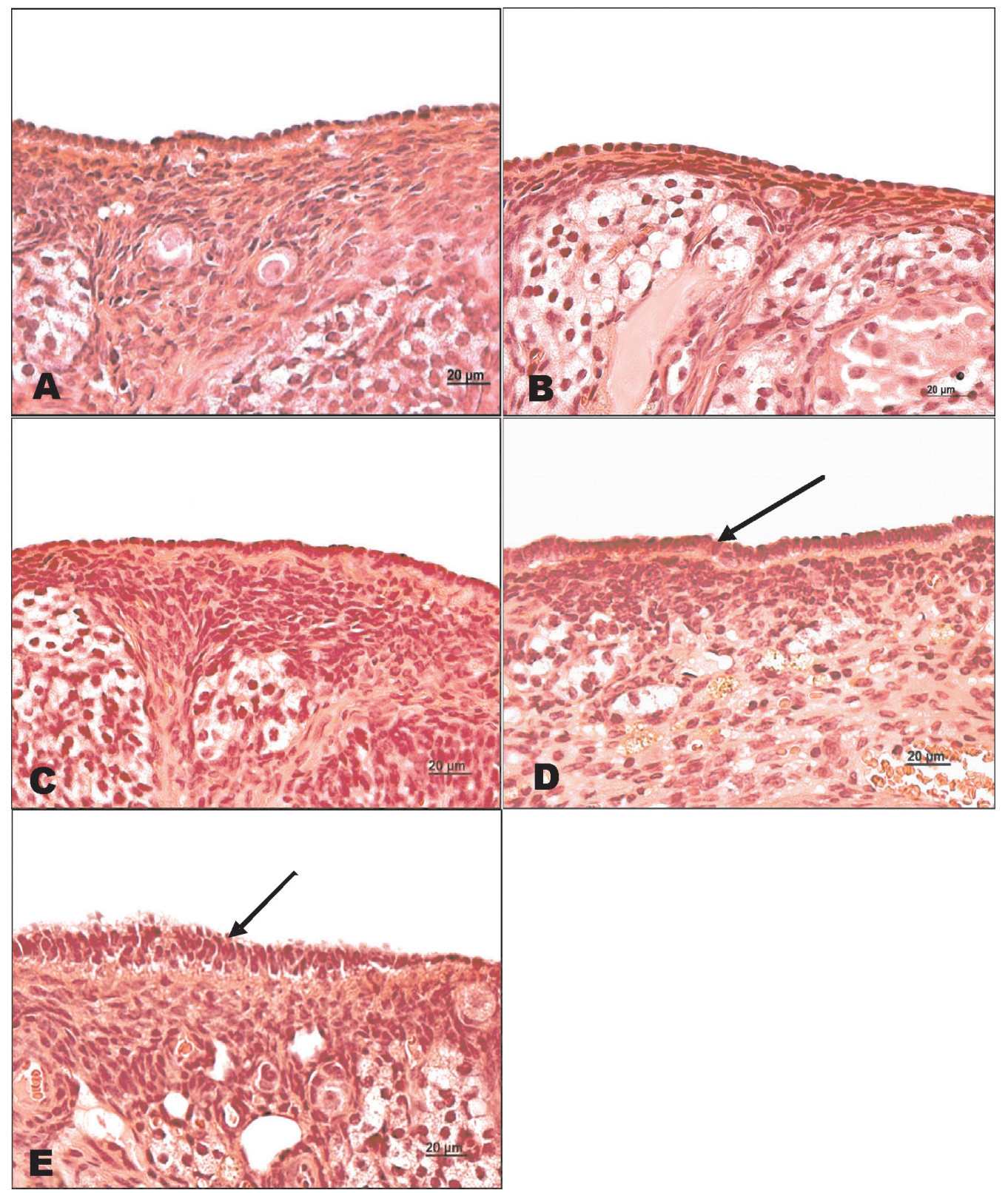

Figure 2 - Photomicrography showing the cortical region of ovaries belonging to the different study groups: A) GPROP, B) GE50 GE1mg and E) GE2mg. The arrows in (D) and (E) indicate thickened superficial epithelia. H.E 260X 
Table 1 - Histomorphometric analysis (mean \pm standard deviation) of rat ovarian surface epithelia. Animal groupings are described in the Materials and Methods section

\begin{tabular}{|c|c|c|c|c|c|}
\hline $\begin{array}{l}\text { Characteristic of ovarian superficial } \\
\text { epithelia }\end{array}$ & $\begin{array}{l}\text { GPROP } \\
(\mathrm{n}=10)\end{array}$ & $\begin{array}{c}\text { GE } 0.05 \mathrm{mg} \\
(\mathrm{n}=10)\end{array}$ & $\begin{array}{c}\text { GE } 0.5 \mathrm{mg} \\
(\mathrm{n}=10)\end{array}$ & $\begin{array}{l}\text { GE 1mg } \\
(\mathrm{n}=10)\end{array}$ & $\begin{array}{l}\text { GE 2mg } \\
(\mathrm{n}=10)\end{array}$ \\
\hline Total analyzed width per ovary $(\mathrm{mm})^{\mathrm{a}}$ & $5.01 \pm 0.23$ & $5.03 \pm 0.11$ & $4.99 \pm 0.23$ & $5.06 \pm 0.16$ & $5.02 \pm 0.17$ \\
\hline Perimeter $(\mathrm{mm})$ & $12.15 \pm 3.11$ & $12.09 \pm 5.69$ & $12.89 \pm 7.65$ & $16.21 \pm 2.39$ & $23.74 \pm 6.81 *$ \\
\hline Thickness $(\mu \mathrm{m})$ & $5.44 \pm 0.30$ & $6.04 \pm 1.36$ & $6.48 \pm 2.68$ & $7.15 \pm 0.126$ & $10.41 \pm 0.18 *$ \\
\hline Area $\left(\mu \mathrm{m}^{2} \times 10^{-3}\right)$ & $29.11 \pm 1.99$ & $30.80 \pm 1.96$ & $31.91 \pm 1.65$ & $33.94 \pm 2.07$ & $56.63 \pm 1.91 *$ \\
\hline
\end{tabular}

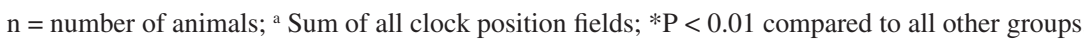

to the other groups $(P<0.01)$. In contrast, the GE0.5mg and GE1mg groups showed little difference in epithelium thickness. Results of the morphometric analysis are shown in Table 1.

\section{DISCUSSION}

Previous studies have identified some risks associated with HRT, including cardiovascular complications and an increase in hormone-dependent cancer. The balance between the benefits of HRT and its risks for women at the menopausal transition and in post-menopause remains controversial. A meta-analysis of research between 1966 and 2006 showed an increased risk of ovarian cancer among users of unopposed estrogen therapy compared to non-users women, with the relative risk of the therapy equal to $1.28(1.18-1.40) .{ }^{36}$ Other studies reinforce the tumorigenic effects of estrogen on ovarian cancer development. ${ }^{37,38}$ This finding is worrisome and brings to light new questions regarding the effects of estrogen on OSE proliferation and cancer. , Elucidating the relationship between estrogen HRT and cancer potentially affects the lives of millions of women and may therefore be considered a significant public health concern. In our study, only high doses of estrogen ( $2 \mathrm{mg} / \mathrm{Kg}$ day) induced the morphometric signs of proliferation in the OSE. However, this dose is 20 -fold higher than conventional HRT doses that induce similar estrogen concentrations in postmenopausal women. ${ }^{36}$ In a previous study with rats we showed that, following treatment with $50 \mu \mathrm{g} / \mathrm{kg}$ of CEE, estrogen levels are close to $32 \mathrm{pg} / \mathrm{ml} .^{39,40}$ These values are similar to those found in postmenopausal women receiving estrogen therapy. ${ }^{40}$

Rat models, and particularly rat models of the chemical carcinogens 7,12-dimethylbenzanthracene (DMBA) and $\mathrm{N}$-methyl-N-nitrosourea (MNU) are the most frequently used to study breast cancer chemoprevention. ${ }^{41-43}$ In intact females, these carcinogens also increase the incidence of epithelial ovarian cancer. This increase is especially strong in the DMBA model, where DMBA is directly applied to the ovarian surface epithelium and promotes neoplasia This local exposure to DMBA leads to epithelial cancer in $30-40 \%$ of the treated rats and to more frequent preneoplastic changes in the ovary. ${ }^{41-43}$

However, although this model is effective, it is based on artificial induction of epithelial growth. Our study was designed to evaluate the proliferation of epithelium after estrogen treatment in senile rats, and this model may be more physiologically relevant than a model involving direct application of DMBA to the ovarian surface.

As female rats age, the number of ovulations and litter size gradually declines, until they eventually cease to cycle and reproduce. ${ }^{44}$ Daily vaginal smear examinations revealed that, starting around 8-12 months of age or even earlier, rats gradually change from regular to irregular cycles, and then to constant estrus and finally to an anestrous state in the oldest rats. ${ }^{44}$ Clemens and Meites ${ }^{45}$ showed that gonadotropin levels, particularly FSH levels, are elevated during this anestrous phase. Therefore, senile female rats may be a good model because they mimic the rise in gonadotropin levels observed in menopausal women.

Since both gonadotropins and steroids control the ovary, these hormones are strong candidates as regulators of OSE proliferation. The fact that hormone receptors are present on the surface of the OSE in several species ${ }^{45-47}$ supports the possibility that they function as regulators, even though interspecies variation of levels of receptor on the OSE suface has been reported. ${ }^{45,49}$ In general, in vivo studies have suggested that gonadotropins $\mathrm{s}^{49,50}$ and estrogen $\mathrm{s}^{51}$ stimulate OSE cell proliferation. The histomorphologic and histomorphometric data in the present study seem to support these findings. The results of in vitro studies, in contrast, are contradictory. Whereas some studies have reported that gonadotropins and estrogens stimulate proliferation of OSE cells in culture, ${ }^{51,52}$ other studies have found no such mitogenic effect on isolated OSE cells, ${ }^{53,54}$ suggesting that the effects of gonadotropin and estrogens are mediated by the local release of other growth-promoting factors. Alternatively, these results may be an artifact of the in vitro nature of the studies.

An interesting finding of our study is that all experimental groups receiving estrogen showed an increase in the number 
of interstitial cells, which are responsible for producing androgens that may increase the proliferation on OSE. Entrapment of ovarian superficial epithelial cells in inclusion cysts increases the likelihood of OSE neoplastic transformation, possibly as a result of the androgen-rich milieu of the stroma. ${ }^{55-56}$ Consistent with this androgen theory, women with polycystic ovary syndrome have a higher risk of developing ovarian cancer, which is probably attributable to anovulation and higher levels of circulating androgen. Although the androgen theory may explain the effect of HRT on the OSE, it is extremely difficult to prove..$^{56}$ One of the limitations of the present study is that it does not provide a rigorous test of this theory. Another limitation is that only high doses of estrogen were observed to induce the proliferation and therefore increase the histomorphometric parameters of OSE. These doses were more than 2-3 times higher than the doses given to women. Therefore, additional mechanisms and factors apart from estrogen may be involved in ovarian cancer, such as growth factors. It is important to emphasize that some women may present with high circulating estrogen levels following infertility treatment with gonadotropins or analogues, and these high levels may place them at greater risk of ovarian neoplasia. ${ }^{57}$

Estrogen is considered to be a risk factor for development of cancer on the ovarian superficial epithelium. ${ }^{38}$ Furthermore, repetitive cycles of epithelial insult and repair during ovulation promote genomic instability, rendering the superficial epithelial layer vulnerable to carcinogenesis. In fact, increased activity of the FSH receptor on ovarian cells and on the epithelial surface at the site of ovulation induces genomic instability, increasing the likelihood that this cellular layer to will show aberrant proliferation. ${ }^{5,8}$ Thus, administration of high-dose estrogen in our experimental model (senile female rats) created the conditions for excessive proliferation of ovarian superficial epithelium, which may have increased the chances of developing ovarian cancer. However, despite promising initial results, further long-term studies are needed to confirm this hypothesis.

\section{REFERENCES}

1. Hensley ML. Epithelial ovarian cancer. Curr Treat Options Oncol. 2002;3:131-41.

2. Tummala MK, McGuire WP. Recurrent ovarian cancer. Clin Adv Hematol Oncol. 2005;3:723-36.

3. Makar AP. Hormone therapy in epithelial ovarian cancer. Endocr Relat Cancer. 2000;7:85-93.

4. Cramer DW, Welch WR. Determinants of ovarian cancer risk. II.Inferences regarding pathogenesis. J Natl Cancer Inst. 1983;71:717-21.

5. Risch HA. Hormonal etiology of epithelial ovarian cancer, with a hypothesis concerning the role of androgens and progesterone. J Natl Cancer Inst. 1998; 90:1774-86.

6. Schildkraut JM, Schwingl PJ, Bastos E, Evanoff A, Hughes C. Epithelial ovarian cancer risk among women with polycystic ovary syndrome. Obstet Gynecol. 1996;88:554-9.

7. Konishi I, Kuroda H, Mandai M. Review: gonadotropins and development of ovarian cancer. Oncology 1999; 57(Suppl. 2):45-8.

8. Ho SM. Estrogen, progesterone and epithelial ovarian cancer. Reprod Biol Endocrinol 2003;1:73.

9. Galhardo CL, Soares JM Jr, Simões RS, Haidar MA, Rodrigues de Lima $\mathrm{G}, \mathrm{Baracat} \mathrm{EC}$. Estrogen effects on the vaginal $\mathrm{pH}$, flora and cytology in late postmenopause after a long period without hormone therapy. Clin Exp Obstet Gynecol. 2006;33:85-9.
10. Grady D, Herrington D, Bittner V, Blumenthal R, DavidsonM, Hlatky $\mathrm{M}$, et al. Cardiovascular disease outcomesduring 6.8 years of hormone therapy: Heart and Estrogen/progestin Replacement Study follow-up (HERS II). JAMA. 2002;288:49-57.

11. WHI (Women's health initiative investigators), 2002. Risks and benefits of estrogen plus progestin in healthy postmenopausal women: principal results from the Women's Health Initiative randomized controlled trial. JAMA. 288:321-33.

12. Clark JH. A critique of Women's Health Initiative Studies. Nucl Recept Signal. 2006;4:23.

13. Lacey JV Jr, Brinton LA, Leitzmann MF, Mouw T, Hollenbeck A, Schatzkin A, Hartge P. Menopausal hormone therapy and ovarian cancer risk in the National Institutes of Health-AARP Diet and Health Study Cohort. J Natl Cancer Inst. 2006;98:1397-405.

14. Rodriguez C, Patel AV, Calle EE, Jacob EJ, Thun MJ. Estrogen replacement therapy and ovarian cancer mortality in a large prospective study of US women. JAMA. 2001;285:1460-5.

15. Syed V, Ulinski G, Mok SC, Ho SM. Reproductive hormone-induced, STAT3-mediated interleukin 6 action in normal and malignant human ovarian surface epithelial cells. J Natl Cancer Inst. 2002;94:617-29.

16. Hall JM, Korach KS. Stromal cell-derived factor 1, a novel target of estrogen receptor action, mediates the mitogenic effects of estradiol in ovarian and breast cancer cells. Mol Endocrinol. 2003;17:792-803. 
17. Choi JH, Choi KC, Auersperg N, Leung PC. Gonadotropins upregulate the epidermal growth factor receptor through activation of mitogen-activated rotein kinases and phosphatidyl-inositol-3-kinase in human ovarian surface epithelial cells. Endocr Relat Cancer. 2005;12:407-21.

18. Chien CH, Wang FF, Hamilton TC. Transcriptional activation of c-myc proto-oncogene by estrogen in human ovarian cancer cells. Mol Cell Endocrinol. 1994;99:11-9.

19. Simpson BJ, Langdon SP, Rabiasz GJ, Macleod KG, Hirst GL, Bartlett $\mathrm{JM}$ et al. Estrogen regulation of transforming growth factor-alpha in ovarian cancer. J Steroid Biochem Mol Biol. 1998;64:137-45.

20. Syed V, Ulinski G, Mok SC, Yiu GK, Ho SM. Expression of gonadotropin receptor and growth responses to key reproductive hormones in normal and malignant human ovarian surface epithelial cells. Cancer Res. 2001;61:6768-76.

21. O'Donnell AJ, Macleod KG, Burns DJ Smyth JF, Langdon SP. Estrogen receptor-alpha mediates gene expression changes and growth response in ovarian cancer cells exposed to estrogen. Endocr Relat Cancer. 2005;12:851-66.

22. Gao N, Nester RA, Sarkar MA. 4-Hydroxy estradiol but not 2- hydroxy estradiol induces expression of hypoxia-inducible factor 1alpha and vascular endothelial growth factor A through phosphatidylinositol 3-kinase/Akt/FRAP pathway in OVCAR-3 and A2780-CP70 human ovarian carcinoma cells. Toxicol Appl Pharmacol. 2004;196:124-35.

23. Kang, SK, Choi, KC, Tai, CJ, Auersperg, N, Leung, PC. Estradiol regulates gonadotropin-releasing hormone $(\mathrm{GnRH})$ and its receptor gene expression and antagonizes the growth inhibitory effects of GnRH in human ovarian surface epithelial and ovarian cancer cells. Endocrinology $2001 ; 142: 580-588$

24. Moll F, Katsaros D, Lazennec G, Hellio N, Roger P, Giacalone PL et al. Estrogen induction and overexpression of fibulin-1C mRNA in ovarian cancer cells. Oncogene 2002;21:1097-107.

25. Murdoch WJ, Van Kirk EA. Steroid hormonal regulation of proliferative, p53 tumor suppressor, and apoptotic responses of sheep ovarian surface epithelial cells. Mol Cell Endocrinol. 2002;186:61-7.

26. Bai, W, Oliveros-Saunders, B, Wang, Q, Acevedo-Duncan, ME, Nicosia, SV. Estrogen stimulation of ovarian surface epithelial cell proliferation In Vitro Cell Dev Biol Anim .2000;36:657-666.

27. Silva EG, Tornos C, Deavers M, Kaisman K, Gray K, Gershenson D. Induction of epithelial neoplasms in the ovaries of guinea pigs by estrogenic stimulation. Gynecol Oncol. 1998;71:240-6.

28. McTavish KJ, Jimenez M, Walters KA, Spaliviero J, Groome NP, Themmen AP et al. Rising follicle-stimulating hormone levels with age accelerate female reproductive failure. Endocrinology. 2007;148:4432-9.

29. Folsom AR, Anderson JP, Ross JA. Estrogen replacement therapy and ovarian cancer. Epidemiology. 2004;15:100-4.

30. Coughlin SS, Giustozzi A, Smith SJ, Lee NC. A meta-analysis of estrogen replacement therapy and risk of epithelial ovarian cancer. J Clin Epidemiol. 2000;53:367-75.

31. Bakken K. Is estrogen therapy of significance for the incidence of breast cancer? Tidsskr Nor Laegeforen. 2004;124:2801.

32. Whittemore AS, Harris R, Itnyre J. Characteristics relating to ovarian cancer risk: collaborative analysis of 12 US case-control studies. II. Invasive epithelial ovarian cancers in white women. Collaborative Ovarian Cancer roup. Am J Epidemiol. 1992;136:1184-203.
33. Garg PP, Kerlikowske K, Subak L, Grady D. Hormone replacement therapy and the risk of epithelial ovarian carcinoma: a meta-analysis. Obstet Gynecol. 1998;92:472-9.

34. Riman T, Dickman PW, Nilsson S, Correia N, Nordlinder H, Magnusson $\mathrm{CM}$ et al. Hormone replacement therapy and the risk of invasive epithelial ovarian cancer in Swedish women. J Natl Cancer Inst. 2002;94:497-504.

35. Bosetti C, Negri E, Franceschi S, Trichopoulos D, Beral V, La Vecchia C. Relationship between postmenopausal hormone replacement therapy and ovarian cancer. JAMA. 2001;285:3089.

36. Women's Health Initiative Steering Committee. Effects of conjugated equine estrogen in postmenopausal women with hysterectomy. The Women's Health Initiative Randomised Controlled Trial. JAMA. 2004;291:1701-2

37. Greiser CM, Greiser EM, Doren M. Menopausal hormone therapy and risk of ovarian cancer: systematic review and meta-analysis. Hum Reprod Update. 2007;13:453-63.

38. La Vecchia C. Estrogen-progestogen replacement therapy and ovarian cancer: an update. Eur J Cancer Prev. 2006;15:490-2

39. de Araujo LF, Soares JM Jr, Simões RS, Calió PL, Oliveira-Filho RM, Simões MJ et al. Effect of conjugated equine estrogens and tamoxifen administration on thyroid gland histomorphology of the rat. Clinics. 2006;61:321-6.

40. Mosquette R, de Jesus Simões M, da Silva ID, Oshima CT, OliveiraFilho RM, Haidar MA, et al. The effects of soy extract on the uterus of castrated adult rats. Maturitas. 2007;56:173-83.

41. Sekiya S, Endoh N, Kikuchi Y, Katoh T, Matsuura A, Iwasawa H, et al. In vivo and in vitro studies of experimental ovarian adenocarcinoma in rats. Cancer Res 1979;39:1108-12.

42. Tunca JC, Erturk E, Bryan GT. Chemical induction of ovarian tumors in rats. Gynecol Oncol 1985;21:54-64.

43. Kato T, Yakushiji M, Tunawaki A, Ide K. A study of experimental ovarian tumors in rats by chemical carcinogen, 20-methylcholanthrene. Kurume Med J. 1973;20:159-67.

44. Huang HH, Marshall S, Meites J. Capacity of old versus young female rats to secrete LH, FSH and prolactin. Biol Reprod. 1976;14:538-43.

45. Clemens JA, Meites J. Neuroendocrine status of old constant-estrous rats.Neuroendocrinology. 1971;7:249-56.

46. Pelletier G, Labrie C, Labrie F.Localization of oestrogen receptor alpha, oestrogen receptor beta and androgen receptors in the rat reproductive organs.J Endocrinol. 2000;165:359-70.

47. Kuroda H, Mandai M, Konishi I, Tsuruta Y, Kusakari T, Kariya M, et al. Human ovarian surface epithelial (OSE) cells express LH/hCG receptors, and hCG inhibits apoptosis of OSE cells via up-regulation of insulin-like growth factor-1.Int J Cancer. 2001;91:309-15.

48. Okada A, Ohta Y, Buchanan DL, Sato T, Inoue S, Hiroi H, et al. Changes in ontogenetic expression of estrogen receptor alpha and not of estrogen receptor beta in the female rat reproductive tract. J Mol Endocrinol. 2002;28:87-97.

49. Hess S, Gulati R, Peluso JJ. Hepatocyte growth factor induces rat ovarian surface epithelial cell mitosis or apoptosis depending on the presence or absence of an extracellular matrix. Endocrinology. 1999;140:2908-16 
50. Stewart SL, Querec TD, Ochman AR, Gruver BN, Bao R, Babb JS, et al. Characterization of a carcinogenesis rat model of ovarian preneoplasia and neoplasia. Cancer Res. 2004;64:8177-83.

51. Bai W, Oliveros-Saunders B, Wang Q, Acevedo-Duncan ME, Nicosia SV. Estrogen stimulation of ovarian surface epithelial cell proliferation. In Vitro Cell Dev Biol Anim. 2000;36:657-66.

52. Murdoch WJ, Van Kirk EA.Steroid hormonal regulation of proliferative, p53 tumor suppressor, and apoptotic responses of sheep ovarian surface epithelial cells.Mol Cell Endocrinol. 2002;186:61-7.

53. Syed V, Ulinski G, Mok SC, Yiu GK, Ho SM. Expression of gonadotropin receptor and growth responses to key reproductive hormones in normal and malignant human ovarian surface epithelial cells. Cancer Res. 2001;61:6768-76
54. Wright JW, Toth-Fejel S, Stouffer RL, Rodland KD. Proliferation of rhesus ovarian surface epithelial cells in culture: lack of mitogenic response to steroid or gonadotropic hormones.Endocrinology. 2002;143:2198-207.

55. Rao BR, Slotman BJ. Endocrine factors in common epithelial ovarian cancer. Endocr Rev. 1991;12:14-26.

56. Risch HA. Hormonal etiology of epithelial ovarian cancer, with a hypothesis concerning the role of androgens and progesterone. J. Natl. Cancer Inst. 1998;90:1774-86.

57. Arslan M, Bocca S, Arslan EO, Duran HE, Stadtmauer L, Oehninger S. Cumulative exposure to high estradiol levels during the follicular phase of IVF cycles negatively affects implantation. J Assist Reprod Genet. 2007;24:111-7. 